\title{
PIBIB E RP: UM OLHAR DE PROFESSORES DE ESPANHOL EM FORMAÇÃO NA UFS
}

\section{PIBIB AND RP: A LOOK FROM SPANISH TEACHERS IN TRAINING AT UFS}

\author{
Acassia dos Anjos Santos Rosa ${ }^{1}$ \\ Universidade Federal de Sergipe (UFS) \\ Doris Cristina Vicente da Silva Matos ${ }^{2}$ \\ Universidade Federal de Sergipe (UFS)
}

\begin{abstract}
RESUMO
Este trabalho está situado na área da Linguística Aplicada, com foco na formação de professores de espanhol. Tem como objetivo analisar as impressões dos graduandos dos Cursos de Letras/ Espanhol e Letras Português/ Espanhol da Universidade Federal de Sergipe que tenham experiência de participação nos seguintes projetos de formação inicial de professores: o Programa Institucional de Bolsas de Iniciação à Docência e o Programa de Residência Pedagógica. A abordagem metodológica seguida é qualitativo-interpretativa e o corpus de investigação é composto por questionário aplicado a graduandos que participaram do PIBID e participavam, no momento da aplicação, do RP. Como resultados, evidenciamos os motivos que levam os graduandos a participarem dos projetos, bem como quais são as percepções dos futuros professores em relação aos dois programas, além de mensurar o papel que os programas ocupam na graduação e como a aproximação entre teoria e prática se efetiva na realização dos projetos. As conclusões apontam que ambos programas são importantes na formação inicial dos professores, oportunizando experiências docentes em níveis diferentes e convergindo para a melhoria na qualidade da formação de professores ainda na graduação, por meio de uma vivência escolar de uma forma ampla, articulando além da teoria e prática, também a ação da práxis pedagógica (FREIRE, 1970).
\end{abstract}

PALAVRAS-CHAVE: Formação de professores; PIBID; RP; Espanhol; Práxis.

\begin{abstract}
This work is situated in the area of Applied Linguistics, focusing on the training of Spanish teachers. It aims to analyse the impressions of the undergraduate students of the Spanish and Portuguese / Spanish Language courses of the Federal University of Sergipe who have experienced participating in the following initial teacher education projects: the Programa Institucional de Bolsas de Iniciação à Docencia and the Programa de Residência Pedagógica. The followed methodological approach was qualitative and interpretative, the research corpus consisted in a questionnaire applied to undergraduates who participated in the PIBID and in the RP at the same time. As a result, we highlight the reasons that lead undergraduates to participate in the projects, as well as the perceptions of future teachers regarding the two programs. It was also possible to measure the role that the programs play in undergraduate and how the approximation between theory and practice is effective in the projects. The conclusions indicate that both programs are important in the initial

\footnotetext{
${ }^{1}$ Doutora em Estudos Linguísticos pela Universidade Federal de Minas Gerais (UFMG). Professora adjunta do Departamento de Letras Estrangeiras da Universidade Federal de Sergipe. E-mail: acassia.aju@hotmail.com

2 Doutora em Língua e Cultura pela Universidade Federal da Bahia (UFBA). Professora associada do Departamento de Letras Estrangeiras e do Programa de Pós-Graduação em Letras da Universidade Federal de Sergipe. E-mail: profadoris_ufs@yahoo.com.br
} 
formation of teachers, providing opportunities for teaching experiences at different levels. In this sense they converge to improve the quality of teacher's education still undergraduate, through a broad school experience, articulating beyond theory and practice the action of pedagogical práxis (FREIRE, 1970).

KEYWORDS: Teacher training; PIBID; RP; Spanish; Práxis.

\section{INTRODUÇÃO}

A formação de professores, de um modo geral, já foi vista como necessidade de aprendizado teórico e conteudista "deixando de lado qualquer preocupação com o preparo didático-pedagógico" (SAVIANI, 2009, p. 143). Aos poucos, as preocupações pedagógicas começaram a ganhar espaço, porém, muitas vezes, isoladas no último ano da formação, conforme aponta Saviani: "isso pode ser observado na organização dos cursos de licenciatura desde o chamado esquema 3+1 das décadas de 1940 e 1950" (SAVIANI, 2009, p. 150). O modelo 3+1 apontado por Saviani (2009) se refere a 3 anos de formação teórica e um ano de componentes pedagógicos, o que inclui o estágio obrigatório.

Porém, mesmo com o início de uma preocupação pedagógica na formação de professores, Cardoso e Mendonça (2019) afirmam que "a formação de professores no Brasil é marcada por dificuldades históricas e estruturais, resultantes do descaso com a educação" (CARDOSO; MENDONÇA, 2019, p. 148). Entre os descasos citados pelos autores estão fragilidades dos cursos de licenciaturas, baixos salários e inadequadas condições de trabalho dos profissionais da educação.

Diante disso, é fundamental a elaboração de políticas públicas que tratem da formação do professor, seja ela inicial ou continuada, para que os cursos de licenciatura possuam mecanismos de aproximação entre a formação teórica e prática dos licenciandos, a fim de motivá-los a seguir na docência. Ressaltamos que o empenho para uma formação docente adequada à realidade escolar é apenas um dos pontos que podem contribuir para uma educação pública de qualidade.

Este trabalho está situado na área da Linguística Aplicada, com foco na formação de professores de espanhol no Brasil e, nos centraremos em dois programas de formação de professores no âmbito da Universidade Federal de Sergipe: o Programa Institucional de Bolsas de Iniciação à Docência (PIBID) e o Programa de Residência Pedagógica (RP), ambos realizados com apoio e incentivo da Coordenação de Aperfeiçoamento de Pessoal de Nível Superior (CAPES). Assim, analisaremos as impressões dos graduandos dos Cursos de Letras/ Espanhol e LetrasPortuguês/ Espanhol da UFS que tenham experiência na participação nos dois projetos. Evidenciaremos os motivos que levam os graduandos a participarem dos projetos, bem como quais são as percepções dos futuros professores em relação aos dois programas. Desta forma, discorreremos sobre o papel que os programas ocupam na graduação e como a aproximação entre teoria e prática se efetivam na realização dos projetos.

O corpus de investigação é composto pela análise qualitativo-interpretativa de um questionário aplicado a 20 (vinte) graduandos que participaram do PIBID e participavam, no momento da aplicação do questionário, do RP. Os resultados apontam que ambos programas são importantes na formação inicial dos professores, oportunizando experiências docentes em níveis diferentes e convergindo para a melhoria na qualidade da formação de professores ainda na graduação, por meio de uma vivência escolar de uma forma ampla, articulando além da teoria e prática, também a ação da práxis pedagógica.

\section{Formação inicial de professores e práxis pedagógica}


Dentre os diversos interesses demonstrados por pesquisadores na área da Linguística Aplicada na contemporaneidade, a formação de professores segue sendo um campo de descobertas e um lugar importante para o desenvolvimento de pesquisas preocupadas com questões relacionadas ao âmbito escolar e/ou acadêmico. O foco no caráter político, emancipador e transformador da educação deve orientar as práxis pedagógicas realizadas pelos professores, apresentando novos caminhos para a construção de sociedades mais justas e igualitárias. Leffa (2008) amplia esse pensamento ao indicar que a formação de professores de línguas estrangeiras envolve aspectos acadêmicos e políticos, pois:

\begin{abstract}
A formação de um professor de línguas estrangeiras envolve o domínio de diferentes áreas do conhecimento, incluindo o domínio da língua que ensina, e o domínio da ação pedagógica necessária para fazer a aprendizagem da língua acontecer na sala de aula. A formação de um profissional competente nessas duas áreas de conhecimento, língua e metodologia, na medida em que envolve a definição do perfil desejado pela sociedade, é mais uma questão política do que acadêmica (LEFFA, 2008, p. 354).
\end{abstract}

Dessa maneira, a sala de aula não pode ser vista como um ambiente isolado, pois ela é reflexo do que ocorre fora dela, e a formação de professores na universidade precisa promover práticas que acarretem o entendimento de que as ações que se realizam nesses ambientes podem produzir mudanças sociais. Como formadoras de professores de espanhol no Brasil, mais especificamente em Sergipe, entendemos que trilhar caminhos que agucem o senso crítico dos professores em formação, será um dos meios para que, futuramente, eles possam atuar no ensino básico com a língua espanhola como meio de inclusão social, de maneira que a língua não seja vista como um mero sistema e passe a ser vivida como promovedora de práticas de linguagem situadas socio/históricamente.

Assim, a formação inicial do professor é o primeiro passo da carreira docente e é na graduação que o estudante tem o primeiro contato com o ambiente acadêmico, se aprofundando em teorias que cercam o seu futuro profissional. Porém, se estas teorias não estão atraladas às práticas docentes, há um enfraquecimento da formação desses professores, que não conhecem a realidade que os aguarda em seu futuro fazer profissional. Por este motivo, se faz primordial o conhecimento da rotina escolar, para que o docente em formação saiba como adaptar-se aos diferentes contextos de ensino.

Freire (1970), em sua pedagogia crítica, aponta para a relação teoria-prática ao utilizar o conceito de práxis e expressando que a verdadeira mudança na vida dos indivíduos somente pode ocorrer através da reflexão crítica e das ações coletivas. A ação tranformadora da realidade pode construir uma conciência crítica coletiva, a partir de uma práxis libertadora e revolucionária: "A verdadeira reflexão crítica origina-se e dialetiza-se na interioridade da "práxis" constitutiva do mundo humano - é também "práxis"” (FREIRE, 1970, p.10).

A teoria precisa fazer parte da experiência vivida de maneira que o conhecimento seja construído entre a ação e a reflexão "sobre o mundo para transformá-lo" (FREIRE, 1970, p. 25). Schlatter (2013, p. 199) ao abordar sobre os professores em uma perspectiva freireana, aponta que:

(...) somos agentes, políticos, críticos, comprometidos e que sabemos escutar para criar possibilidades para a construção do conhecimento. Insisto, portanto, que nosso maior desafio é criar oportunidades constantes de reflexão coletiva para que possamos relacionar teoria e prática, conscientizando-nos sobre nosso fazer pedagógico e aperfeiçoando nossa capacidade de adaptar nossa atuação a diferentes contextos de ensino, valorizando os conhecimentos de todos e criando condições para que todos possam aprender.

Tais oportunidades de reflexão coletiva criadas na práxis pedagógica são fundamentais para que o fazer pedagógico seja emancipador. Quando partimos do processo de educação 
linguística em espanhol, o futuro professor precisa compreender a complexidade que envolve estar em uma sala de aula com diversos alunos, aproximando a realidade da língua estudada à realidade dos discentes. Freire (2001, p. 42) salienta que para tornarse professor é preciso uma reflexão crítica sobre a prática, exigindo uma dinâmica entre "o fazer e o pensar sobre o fazer".

Em outras palavras, a formação do professor não está limitada a aprendizagem de conteúdos teóricos isolados da prática reflexiva, mas sim estreitamente ligada a ela, visto que "é pensando criticamente a prática de hoje ou de ontem que se pode melhorar a próxima prática" (FREIRE, 2001 p. 43). Desta forma, o futuro docente que experimenta diversas situações de ensino ainda no período da graduação pode contribuir para sua práxis pedagógica, visto que há uma diversidade em sua formação que aproxima a teoria da prática e da ação.

Rosa (2017) afirma que "uma formação inicial bem consolidada é indispensável para a atuação profissional do professor, porém, a graduação abarca um espaço de tempo pequeno para lidar com as complexidades do cotidiano docente." (ROSA, 2017. p. 15). Inferimos assim, que apenas as disciplinas teóricas vistas na graduação podem não ser suficientes para lidar com a complexidade que está atrelada a formação inicial de um professor. Nesse sentido, é preciso um contato prático, mas ao mesmo tempo monitorado, para as possíveis situações adversas que possam ocorrer.

Não podemos esquecer também que outros problemas podem ser citados quando se trata de formação inicial do professor, como por exemplo, a superlotação nas salas, a falta de rescursos e de professores nas universidades. Assim, a união entre teoria e prática, e acompanhamento mais aproximado dos graduandos podem ser possíveis em programas que proporcionem a imersão no cotidiano escolar, como por exemplo no Programa Institucional de Bolsas de Iniciação à Docência (PIBID) e no Programa de Residência Pedagógica (RP), detalhados na próxima seção. Garcez (2013, p. 221) reitera sobre a construção de saberes locais a partir da prática com o PIBID que:

\footnotetext{
$\mathrm{Na}$ formação inicial, talvez pudéssemos avançar ao propiciarmos mais oportunidades de contato direto dos estudantes/professores em formação com a realidade escolar para que uma prática incipiente do aprendiz de professor possa de fato se beneficiar de toda a informação que as especialidades acadêmicas têm a oferecer ao longo do currículo universitário, mas que caem no vácuo e no esquecimento sem esse terreno.
}

O terreno da escola é o local fértil para a construção da práxis pedagógica e, no caso específico dos professores de línguas, os programas possibilitam que os graduandos possam usar o idioma em contexto de ensino, fato que, para muitos estudantes, é um desafio, pois nem sempre eles têm segurança e domínio do idioma, antes de ingressar na graduação. Com isso, os programas permitem experimentações assistidas e trocas de experiências, fato que contribui para a segurança da atuação dos futuros professores, bem como novas experiências para professores que estão em sala de aula.

Consideramos que a formação inicial deve configurar-se como o ponto de partida para aqueles que desejam ensinar, os graduandos são estimulados a compreender que uma formação inicial bem consolidada é aquela que fomenta a busca por novos saberes e constante troca de experiências entre os professores em serviço, fato também proporcionado pelos programas que buscam uma parceria entre universidade e escola. Na próxima seção detalharemos dois desses programas que possibilitam uma práxis pedagógica de compartilhamento de experiências e saberes.

\section{PIBID E RP: breve histórico dos programas}

O Programa Institucional de Bolsas de Iniciação à Docência (PIBID) e o Programa de Residência Pedagógica (RP) são duas possibilidades de Projetos que os graduandos de Cursos de 
Letras/ Espanhol e Letras- Português/ Espanhol da Universidade Federal de Sergipe (UFS) possuem para terem inserção no ambiente escolar ainda durante sua formação inicial, de maneira a incentivar a formação docente em nível superior para a educação básica. Na UFS, além desses dois Programas, existem outras possibilidades através de Projetos diversos desenvolvidos por professores, entretanto, a prática pedagógica obrigatória no currículo ocorre durante as disciplinas de Estágio Supervisionado.

Entendemos que, ao participar dos Programas PIBID e/ou RP, os graduandos terão a oportunidade de vivenciar a realidade do ambiente escolar antes ou concomitantemente com as disciplinas de estágio, possibilitando o aprimoramento de sua formação docente, além da oportunidade de conhecer a realidade social de seu futuro campo de trabalho. Também é permitido "o diálogo entre as disciplinas cursadas durante a graduação, ensejando as mudanças que se fizerem necessárias na formação desses futuros profissionais, em consonância com a realidade encontrada nos campos de estágio" (MATOS, 2015, p.94).

O Programa Institucional de Bolsas de Iniciação à Docência (PIBID) teve início na UFS no ano de 2007, entretanto a área de espanhol ingressou no Programa no ano de 2014. De 2014 a 2018, o público alvo eram alunos matriculados em qualquer período do Curso de licenciatura e, a partir de agosto de 2018, com o edital CAPES n ${ }^{\circ} 7 / 2018$, somente alunos regularmente matriculados na primeira metade do Curso, sendo considerados os discentes que não tenham concluído mais de 60\% da carga horária regimental do Curso.

Quando iniciou o último edital em agosto de 2018, o Projeto da área de espanhol contava com dois núcleos compostos por 30 bolsistas de iniciação à docência em cada, totalizando 60, sendo 48 bolsistas e 12 voluntários. Cada núcleo era coordenado por uma professora efetiva de espanhol da UFS, totalizando duas coordenadoras, e cada núcleo possuía três professores supervisores, que são professores efetivos de escolas estaduais indicadas pela Secretaria de Estado da Educação, totalizando seis supervisores, além de uma coordenadora institucional.

Os participantes do programa recebem bolsas através da Coordenação de Aperfeiçoamento de Pessoal de Nível Superior (CAPES) e o objetivo é a inserção dos alunos no universo das escolas públicas desde o início de sua formação para o desenvolvimento de projetos didáticos-pedagógicos orientados pelo professor da Instituição de Ensino Superior (IES) e da escola participante do programa. Desta forma, o subprojeto de Espanhol proporciona aos futuros professores de língua espanhola o contato com as principais discussões teórico-metodológicas desenvolvidas na área da educação linguística em Língua Espanhola no Brasil, para melhor desenvolvimento das práticas pedagógicas dos futuros docentes.

O Programa de Residência Pedagógica (RP) tem seu surgimento no ano de 2018, tendo como público alvo os alunos matriculados a partir da segunda metade do Curso de licenciatura. $\mathrm{O}$ RP é fruto da repartição do PIBID, visto que antes tal programa abrangia licenciados de quaisquer períodos da graduação. $O$ público alvo são os estudantes da segunda metade do curso, de preferência os que estejam cursando as disciplinas de estágio obrigatório. No caso da UFS, no curso de Letras espanhol alunos que estejam cursando a partir do $5^{\circ}$ semestre e do curso do Letras português espanhol alunos que estejam cursando a partir do $4^{\circ}$ semestre. Os participantes do programa também recebem bolsas através da CAPES.

A estrutura de funcionamento de assemelha ao PIBID. Em agosto de 2018, início do programa, o núcleo de espanhol da UFS contava com um núcleo composto por 30 residentes, sendo 24 bolsistas, três preceptores que atuam como professores da educação básica nas escolas indicadas pela secretaria de educação (seja estadual ou municipal); um coordenador de área e um coordenador institucional. Nessa configuração, o programa passou a contar com membros voluntários, fator bastante negativo, visto que os alunos possuem um custo para deslocamento até a escola, bem como alimentação e demais despesas pessoais. Além disso, um núcleo com 30 residentes dificulta o acompanhamento do coordenador de área em todas as ações que os residentes exercem no programa. 
De acordo com a Portaria CAPES n ${ }^{\circ} 175$, de 7 de agosto de 2018, os graduandos devem cumprir uma carga horária de 440 horas divididas nos 18 meses de vigência do programa. Da carga horária global, no mínimo 100 horas devem ser de regência de classe. Esse ponto é bastante delicado pois o edital do programa não previu adequação da quantidade de horas pela carga horária que a disciplina possui na escola. Assim, disciplinas como espanhol, por exemplo, que possuem apenas uma hora de aula por semana exigiu dos residentes a execução de projetos extra para o cumprimento das horas. Ressaltamos que nem todas as escolas possuem várias turmas para que os residentes pudessem cumprir a carga apenas nas aulas regulares.

Outro ponto delicado, determinado pela Portaria CAPES no 175, de 7 de agosto de 2018, é a devolução de todas as bolsas recebidas no programa caso o aluno não consiga cumprir a carga horária determinada. A portaria não considera que o graduando pode não se identificar com o trabalho docente e abandonar o curso, por exemplo, ou mesmo colar grau antecipadamente por diversos motivos. Em tais casos, todas as bolsas deveriam ser devolvidas com a correção de juros prevista.

Por sua configuração, o RP se assemelha ao estágio obrigatório dos alunos com a previsão de observação, imersão na escola, planejamento, aulas ministradas e elaboração do relatório final que comprove a execução das horas exigidas. Igual ao estágio, o RP oferece a possibilidade de imersão apenas na segunda metade do curso, o que deixaria os graduandos distantes da escola nos primeiros anos da licenciatura. Por este motivo, a participação do graduando nos dois programas (PIBID E RP), possibilita o contato com o ambiente escolar do início ao fim da graduação, fato que proporciona uma imersão e uma vivência mais profunda da realidade escolar do que apenas no contato com o estágio obrigatório. $\mathrm{Na}$ próxima seção, apresentaremos a análise dos dois programas aos olhos dos graduandos participantes.

\section{PIBID E RP aos olhos dos graduandos}

Os participantes da pesquisa foram os alunos dos cursos de Letras Espanhol e Letras Português/Espanhol da UFS, integrantes do RP e que tivessem participado também do PIBID. Dos trinta residentes que atuavam no RP em janeiro de 2019, vinte graduandos participaram da pesquisa de maneira voluntária. Para nossa análise, ordenamos os participantes de 1 (um) a 20 (vinte), de acordo com o recebimento das respostas dos participantes.

A participação dos graduandos consistiu em responder um questionário elaborado exclusivamente para esta pesquisa. O questionário foi escolhido pois segundo Silva et al (1997, p. 410) o "questionário seria uma forma organizada e previamente estruturada de coletar na população pesquisada informações adicionais e complementares sobre determinado assunto sobre o qual já se detém certo grau de domínio." O questionário foi enviado por e-mail, como também as respostas foram recebidas por e-mail, fato que permitiu que, ao mesmo tempo, várias pessoas participem da pesquisa sem que a resposta de uma influenciasse na resposta da outra. Selecionamos algumas respostas que consideramos mais significativas para proceder à análise qualitativa. A seguir, apresentamos um quadro com as perguntas realizadas e seus objetivos, ou por grupo de perguntas presentes no questionário.

Quadro 1: Questionário direcionado aos participantes da pesquisa

\begin{tabular}{|l|l|}
\hline \multicolumn{1}{|c|}{ PERGUNTAS } & \multicolumn{1}{c|}{ OBJETIVOS } \\
\hline 1. Qual sua idade? & Traçar o perfil do participante \\
\hline 2. Qual seu curso? & \\
\hline
\end{tabular}




\begin{tabular}{|c|c|}
\hline 3. Qual foi seu tempo de participação no PIBID? & \\
\hline $\begin{array}{l}\text { 4. Há quanto tempo você participa do Residência } \\
\text { Pedagógica? }\end{array}$ & \\
\hline 5. Você é bolsista? & \\
\hline $\begin{array}{l}\text { 6. Porque você resolveu participar dos programas de } \\
\text { formação à docência (PIBID e RP)? }\end{array}$ & $\begin{array}{l}\text { Identificar os atrativos e motivações para } \\
\text { ingresso nos programas. }\end{array}$ \\
\hline $\begin{array}{l}\text { 7. Comparando os programas PIBID e RP: } \\
\text { a. Quais as principais diferenças? } \\
\text { b. Quais as principais semelhanças? } \\
\text { c. Com qual você mais se identificou (até o momento)? } \\
\text { d. Comente as contribuições do PIBID em sua formação. } \\
\text { e. Comente as contribuições do RP em sua formação até } \\
\text { o momento. }\end{array}$ & $\begin{array}{l}\text { Identificar aproximação e distanciamento } \\
\text { entre os programas, bem como perceber as } \\
\text { contribuições oferecidas aos graduandos. }\end{array}$ \\
\hline $\begin{array}{l}\text { f. Você tem alguma crítica ou sugestão a fazer de maneira } \\
\text { a aperfeiçoar os Programas? }\end{array}$ & $\begin{array}{l}\text { Espaço livre para que os participantes } \\
\text { pudessem dar suas sugestões de melhora } \\
\text { para os programas. }\end{array}$ \\
\hline $\begin{array}{l}\text { 8. Você já cursou ou está cursando alguma disciplina de } \\
\text { estágio? } \\
\text { a. Se sim, as atividades realizadas no RP e/ou no PIBID } \\
\text { são as mesmas de estágio? Explique. }\end{array}$ & $\begin{array}{l}\text { Identificar as aproximações entre RP e } \\
\text { estágio obrigatório. }\end{array}$ \\
\hline
\end{tabular}

Fonte: elaboração própria

A maior parte dos participantes da pesquisa, 70\% (setenta por cento), o equivalente a 14 (catorze) graduandos, pertencia ao curso de dupla habilitação. A idade dos participantes variou entre 19 (dezenove) e 32 (trinta e dois) anos, sendo que 45\% (quarenta e cinco por cento) possuem entre 21 (vinte e um) e 22 (vinte e dois) anos. A média de participação no PIBID foi de 18 (dezoito) meses e o tempo que eles estavam no RP, foi exatamente igual, 5 (cinco) meses, visto que eles estavam no primeiro grupo do programa.

Sobre a motivação dos participantes em participar dos programas (pergunta 6), todos responderam que resolveram participar para praticar seus conhecimentos, por conta do contato em sala de aula e possibilidade de união entre teoria e prática, o que indica um primeiro passo para a construção da práxis defendida por Freire (1970):

Inicialmente no PIBID, por querer entender na prática se eu realmente queria seguir a carreira docente, ademais de aperfeiçoar as teorias trabalhadas nas classes. E o Residência foi por querer dar continuidade a esses aprendizados (participante 1, resposta 6).

Ingressei no PIBID ainda caloura, quando estava no primeiro período da graduação, por ter dúvidas se realmente queria ser professora. Como nunca foi minha primeira opção de curso ser professora, tinha dúvida se conseguiria da (sic) aula e acreditava que o projeto fosse me ajudar nessa descoberta, e vejo que ajudou... pois ainda sigo firme na graduação e agora quase formanda. O que me levou a participar da residência pedagógica foi a vontade de querer continuar aprendendo e dando aulas, sei que me ajudará a ser uma profissional melhor o que almejo, além de poder contribuir com a educação pública, sendo que sou fruto da mesma (participante 17 , resposta 6).

A participante 17 indica que quando ingressou no PIBID não sabia se queria ser professora, revelando que o projeto a ajudou na descoberta da profissão. Já o ingresso no RP se deu para continuar aprendendo e ser uma profissional melhor, fato que corrobora com a práxis pedagógica de Freire (1970) que prevê uma reflexão na ação docente. Assim, é possível inferir que os programas auxiliam os graduandos a entrarem em contato com a prática docente em escolas públicas, auxiliando os licenciandos a se reconhecerem em suas carreiras, conforme apontam as participantes 1 e 17. Também é possível perceber que a participante 17, ao indicar que poderá contribuir com a 
educação pública e que é fruto dela, entende o caráter político da profissão, como possibilidade de promover sua inclusão social e dos alunos que terá contato durante sua práxis pedagógica.

Os participantes da pesquisa apontaram quais as principais semelhanças entre os programas. Uma questão bastante citada foi a preocupação na formação docente que ambos os projetos proporcionam:

Uma das principais semelhanças é a ênfase na formação, do aluno graduando, em atentar-se quanto aos documentos que regem as leis da educação nas escolas públicas (...) (participante 8 , resposta $7 \mathrm{~b}$ ).

Além disso, os participantes citam a estrutura dos projetos, como o acompanhamento que recebem tanto do professor da educação básica, como do professor do ensino superior. Os participantes apontam, ainda, uma reflexão sobre sua prática, o que pode fomentar a melhora sobre as futuras ações, conforme defende Freire (2001).

Ambas têm o mesmo propósito: a inserção, experimentação e reflexão acerca dos desafios recorrentes no ambiente educacional. Além do mais, os mesmos seguem com semelhanças no edital como o acompanhamento de um professor da escola e por um docente da universidade (participante 2, resposta $7 b)$.

Como principal diferença entre os programas, é possível assinalar que no RP há uma ênfase na prática docente, por meio da determinação de cumprimento de 100 horas de regência, fato que proporciona uma experiência enriquecedora com a práxis pedagógica. Desta forma, os residentes podem atuar de forma mais autônoma, na medida em que ganham um contato mais direto com os alunos da educação básica, bem como vivem a rotina escolar do professor, conforme podemos observar nas respostas a seguir.

A autonomia na sala, o que não havia no PIBID e o fato de ministrarmos, planejarmos e prepararmos a aula (participante 4 , resposta $7 \mathrm{a}$ ).

Até o momento eu acredito que há uma grande diferença (...) podemos lecionar mais e realmente ter uma vivência do tamanho do trabalho de um professor (participante 6, resposta 7a).

(...) no RP, temos uma bagagem de conhecimentos muito maior que no PIBID, vejo isso como uma ferramenta a mais para nos "lapidar" como profissionais. No RP, subentendo que já temos experiências de estágios, por exemplo; e isto nos traz mais oportunidade ainda de aprimorarmos os conhecimentos que adquirimos na sala de aula e do PIBID (para o caso de quem conseguiu a oportunidade de ser pibidiano) (participante 8 , resposta 7 a).

Reiteramos que, com a experiência do RP, os participantes apontam não somente uma maior autonomia, como também a compreensão da dimensão do trabalho com o professor. Assim, percebe-se que as aulas teóricas da graduação não seriam suficientes para que os licenciandos tivessem tais experiências de formação, visto que apenas o contato direto com sala de aula proporciona tais reflexões. O PIBID torna-se, para os participantes, o primeiro contato com a escola, o que os fazem se aproximar da profissão de professor; o RP, por sua vez, proporciona um maior contato e experiência didática. Essa relação fica explícita ao analisarmos as respostas sobre a identificação dos alunos com os programas, conforme fragmento a seguir:

(...) me identifiquei com o PIBID por estar no início da formação, pela elaboração de oficinas com temáticas sociais, pela leitura e discussão dos temas... Ao mesmo tempo sentia que faltava algo em relação à regência de classe, mas compreendia que não tinha formação suficiente para ministrar mais aulas. Agora, no RP, me identifico com o programa justamente por estar mais vezes ministrando aulas (participante 19, resposta 7c).

As respostas analisadas indicam uma formação inicial voltada para a práxis pedagógica proposta por Freire (1970), na medida em que proporciona aos graduandos uma maior 
possibilidade de reflexão sobre sua formação e prática discente desde os primeiros períodos da graduação. Essa possibilidade de atuação, fomenta a reflexão crítica apontada por Freire (2001) e distancia-se do modelo de formação 3+1 apontado por Saviani (2009), no qual os cursos ofereciam três anos de formação teórica e um ano de prática no estágio, fato explicitado pelos participantes da pesquisa, conforme respostas abaixo descritas.

Nas disciplinas de estágio, fazemos poucas horas de regência por causa das divergências entre os calendários da UFS e das escolas. Lemos alguns textos teóricos, temos as contribuições da professora e produzimos relatórios. A depender do professor, é possível que outras atividades sejam desenvolvidas. Nos programas, temos mais horas de regência, mais tempo de acompanhamento dos alunos e análise do processo de ensino/aprendizagem e contamos também com a devolutiva dos preceptores (participante 19, resposta 8).

As atividades desses programas ainda exigem mais do futuro docente e contribuem ainda mais na formação do professor que o próprio estágio (participante 20 , resposta 8 ).

A participante 19 cita a dificuldade de encontro entre o calendário letivo da UFS e o calendário da rede básica de ensino. Essa situação de divergência de calendário ocorre por vários motivos, como por exemplo greve de diversas naturezas, o que acarreta dificuldade na hora do estágio de regência, limitado a um semestre acadêmico. A participação nos programas de fomento a formação de professores proporciona um contato mais prolongado com a sala de aula que os estágios obrigatórios; por isso, problemas como greve e falta de aula não impedem que a experiência ocorra, visto que os licenciandos podem vivenciar um ou mais anos letivos completos na escola. A seguir, as respostas evidenciam a comparação entre as atividades realizadas nos programas e nas disciplinas de estágio.

(...) No estágio, quando assumimos a turma, apenas ministramos as aulas de acordo com o planejamento pronto do professor regente. Não temos a oportunidade de planejar coisas novas e, muitas vezes, nem conseguimos executar o que nos foi atribuído dentro daquele curto período. No RP temos a possibilidade de planejar, ou seja, construir um plano com o professor, discutir com alguém que está um pouco a nossa frente, buscar as melhores alternativas para propor uma experiência positiva para todos (estagiários, professor regente e alunos) e, assim, aprender a ser professor na sua totalidade e não apenas na ministração de uma carga horária limitada (participante 3, resposta 8).

São semelhantes já que os objetivos são os mesmos, no entanto, em meio a ambos os programas conseguimos desenvolver um maior número de atividades, temos um acompanhamento, tanto do coordenados quanto do supervisor na escola; enquanto no estágio tudo é limitado à uma determinada carga-horária que deve ser cumprida- bastante parecida com o RP atual, com a diferença de que este pode ser desenvolvido em um período de tempo mais amplo (participante 14, resposta 8).

Acredito que as atividades são as mesmas, no entanto, somente com os estágios não seria possível ter a visão que tenho hoje de como é o funcionamento do ensino de uma forma mais prática antes mesmo de concluir a graduação, ou seja, o que eu quero é dizer é que os estágios são importantes, porém muito mais superficiais que os dois programas (participante 18, resposta 8).

Os participantes ressaltam que os programas concedem mais tempo na escola, assim, as atividades são desenvolvidas com mais planejamento, favorecendo um aprofundamento na prática docente. Porém, a estrutura burocrática do RP que prevê devolução de bolsas para alunos que não cumpram o plano de 440 horas e a regência de no mínimo 100 horas para qualquer licenciatura são criticados pelos residentes. Uma disciplina como espanhol, por exemplo, possui apenas uma hora semanal nos currículos de cada série do ensino médio; como são 10 residentes por escola, nem sempre é possível que o residente atue em mais de uma turma na escola, burocratizando o cumprimento das horas. 
Acho que o edital do RP deveria ser reanalisado pelas autoridades competentes. Devolução de bolsas deveria ser penalidade (...) não para quem chega ao final do curso e precisa colar grau, até porque o próprio programa acolhe alunos em períodos finais de graduação, logo, é contraditório da parte do governo não aceitar a justificativa de um término de curso (participante 3 , resposta 7f).

(...) no RP acredito que a mudança deve ser referente à questões burocráticas, e sei que isto não diz respeito ao coordenador da área e sim aos elaboradores do programa, que aparentam priorizar a quantidade de atividades desenvolvidas em detrimento do conhecimento adquirido (participante 3, resposta $7 f)$.

Creio que o RP exige um número muito grande de horas, de maneira que se torna cansativo conciliar o curso com todas as atividades do programa (participante 20 , resposta $7 \mathrm{f}$ ).

Outro ponto criticado pelos residentes é o fato da possibilidade de voluntários nos programas. Até 2018, como vimos, o PIBID era formado por grupos de até 20 (vinte) bolsistas, 2 (dois) supervisores e 1 (um) coordenador de área, porém, a nova configuração no PIBID, estendida ao RP, permite até 30 (trinta) alunos por grupo, 3 (três) supervisores e 1 (um) coordenador de área, sendo que 24 (vinte e quatro) alunos são bolsistas e até 6 (seis) voluntários. Tal reestruturação não apenas aumentou a demanda de trabalho do coordenador de área, mas também coloca os graduandos em situações desiguais de atuação, visto que necessita de outro tipo de financiamento para se manter no programa.

A existência de alunos voluntários é um enfraquecimento ao programa, pois deixa os alunos em situação de desigualdade de condições de atuação (participante 2, resposta 7f).

Seria interessante que todos os alunos voltassem a ser bolsistas, para não haver momentos de desigualdade, como na compra das camisas (participante 12, resposta 7f).

(...) o número de bolsistas por grupo. Não que eu esteja enfrentando problemas relacionados a isso, mas não tenho dúvida de que seja desgastante para os coordenadores, podendo inclusive prejudicar no acompanhamento de cada participante (participante 19 , resposta $7 \mathrm{f}$ ).

A participante 12 cita uma situação em que coloca os alunos em situação constrangedora, a compra das camisas. Os grupos costumam se organizar e comprar camisas para a identificação nas escolas, feita com financiamento próprio, o aluno que não é bolsista, nem sempre possui recursos para a compra, o que gera um impasse quanto a proposta de tal aquisição. Essa situação poderia ser minimizada com o próprio custeio do programa. Porém, a verba recebida não permite a compra de camisas, nem de materiais permanentes, o que limita o gasto do orçamento oferecido.

(...) Seria importante se recebêssemos verba para a compra de aparelhos de Datashow, impressoras ou outros materiais para utilizarmos nas atividades do programa, pois, em algumas escolas da rede pública, a ausência de equipamentos é um problema. Ao término do programa, os materiais adquiridos poderiam ser doados para o departamento do curso e permaneceriam à disposição dos alunos ou, talvez, para alguma escola que necessitasse desde que tudo fosse registrado com termos e controles de patrimônio. É um sonho, mas não deixa de ser uma sugestão (participante 3, resposta 7f).

As críticas apontadas buscam aperfeiçoar o andamento dos programas que, como podemos observar, trazem vários benefícios aos participantes, dentre os quais destacamos a práxis pedagógica. Por isso, os participantes apontam a sugestão de maior divulgação das atividades realizadas, para que a comunidade em geral possa conhecer os benefícios proporcionados pelos programas. As ações poderiam vislumbrar práticas interdisciplinares, aproximando as diversas disciplinas ofertadas nas escolas. A sugestão, descrita a seguir, apresenta como a participação no programa fomenta a criatividade dos graduandos, fazendo surgir ideias de projetos a serem implementados nas escolas. 
A Sugestão que tenho é que pudéssemos disseminar mais ainda o quão tais programas são enriquecedores para nossa formação, divulgando não só nas próprias graduações, mas, desde o ensino médio (...). Se fosse possível, chegássemos até as mídias com o propósito de divulgar os resultados de ambos os projetos e como seus resultados são positivos. Nas escolas, poderia existir o "o dia do PIBID". Quase que obrigatoriamente envolvendo dinâmicas com todas as disciplinas, com o intuito de correlacioná-las, fazendo com que além de propagar a marca do PIBID, estaríamos intercomunicando as disciplinas (participante 8 , resposta $7 \mathrm{f}$ ).

A oferta dos programas nos cursos de licenciatura faz que a profissão docente seja vivenciada e aperfeiçoada pelos futuros professores, que possuem supervisão na escola e na universidade. Desta forma, a construção do conhecimento ocorre na ação e na reflexão (FREIRE, 1970), fomentando a formação de futuros professores comprometidos com a educação pública e de qualidade. Mesmo que tenham pontos em comum, os dois programas possuem objetivos diferentes e ambos são importantes na formação inicial dos professores nas universidades, ensejando oportunidades de práxis pedagógicas baseadas na troca de experiências e saberes em escolas públicas, através da vivência da realidade docente.

\section{CONSIDERAÇÕES FINAIS}

Perante os resultados apontados na pesquisa realizada com professores de espanhol em formação que participaram dos Programas PIBID e RP, podemos perceber que ambos promovem a inserção dos estudantes no ambiente escolar de maneira profícua. A possibilidade de estarem imersos, através do PIBID, na educação básica desde o começo da graduação oportuniza a vivência inicial da realidade escolar e, consequentemente, uma maior certeza de que estão seguindo a profissão adequada. Da mesma maneira, a continuidade dessa vivência, através do RP, promove o aprofundamento de práticas docentes mais intensas, com maior experiência em processos pedagógicos nas escolas.

Como coordenadoras dos Programas, entendemos que as respostas aos questionários refletem a importância de ambos Projetos para a melhoria da formação de professores nas universidades públicas brasileiras, em especial, a dos professores de espanhol. É visível que a qualidade da formação docente é elevada quando o graduando tem a oportunidade de participar de um dos Programas ou dos dois, pois, ao chegar nas disciplinas de estágio, já conseguem atuar de maneira mais proveitosa ao elaborar planos de curso, de aula, unidades didáticas e demais atividades referentes ao fazer docente.

É preciso aproximar mais a universidade das escolas de ensino básico, para que os discursos ditos teóricos se aproximem das práticas que se estabelecem no fazer diário das escolas, de maneira que a práxis pedagógica seja um elemento construído na ação. A formação inicial de professores de espanhol de qualidade não pode, dessa maneira, restringir-se às disciplinas de estágio, que ocorrem a partir de determinado período da formação, mas sim estar vinculada às experiências docentes desde o início do caminho de formação desses professores. Nosso olhar como formadoras na universidade é refletido através do olhar de nossos professores em formação, tanto na universidade, quanto nas escolas.

\section{REFERÊNCIAS BIBLIOGRÁFICAS}

BRASIL. Ministério da Educação. Portaria Coordenação de Aperfeiçoamento de Pessoal de Ensino Superior $N^{\circ} 175$ de 7 de agosto de 2018. Altera o Anexo I da Portaria no 45, de 12 de março de 2018, que regulamenta a concessão de bolsas e o regime de colaboração no Programa de Residência Pedagógica e no Programa Institucional de Bolsa de Iniciação à Docência (Pibid). Diário Oficial 
da União 09/09/2018. Disponível em: https://abmes.org.br/legislacoes/detalhe/2568/portariacapes-n-175 acesso em 20 de setembro de 2019.

Ministério da Educação. Edital Coordenação de Aperfeiçoamento de Pessoal de Ensino Superior $n^{\circ}$ 7/2018. Chamada pública para apresentação de propostas do Programa Institucional de Bolsa de Iniciação à Docência - PIBID. 01/03/2018. Disponível em: https://www.capes.gov.br/images/stories/download/editais/01032018-Edital-7-2018PIBID.pdf acesso em 02 de dezembro de 2019.

CARDOSO, Nilson de Souza; MENDONÇA, Sueli Guadelupe de Lima. A trajetória de atuação do FORPIBID-RP: entre inovar a formação e resistir aos ataques. Revista Anfope. Associação Nacional pela Formação de Profissionais da Educação. Formação em Movimento * v.1, n.1, p.146152, jan./jun. 2019.

FREIRE, Paulo. Pedagogia do oprimido. Rio de Janeiro: Paz e Terra, 1970.

Terra, 2001.

Pedagogia da autonomia: saberes necessários à prática educativa. 20 ed. São Paulo: Paz e

GARCEZ, Pedro de Moraes. Pedro de Moraes Garcez. In: SILVA, Kleber Aparecido da; ARAGÃO, Rodrigo Camargo (Orgs.). Conversas com formadores de professores de linguas: avanços e desafios. Campinas, SP: Pontes Editores, 2013, p. 215-228.

LEFFA, Vilson José. Aspectos políticos da formação do professor de línguas estrangeiras. In: LEFFA, Vilson José. (Org.). O professor de linguas estrangeiras: construindo a profissão. Pelotas: EDUCAT, 2008., p. 353-376.

MATOS, Doris Cristina Vicente da Silva. Estágio Supervisionado X PIBID: duas faces da mesma moeda? Revista (Con)Textos Linguísticos, v. 9, n. 14, 2015, p. 93-105.

ROSA, Acassia dos Anjos Santos. Perfil dos professores de espanbol participantes de um curso de formação continuada e sua condição docente. GT8- Espaços Educativos, Currículos e Formação Docente (Saberes e Práticas). Anais do $10^{\circ}$ encontro internacional de formação de professores. v. 10, n. 1. 2017.

SAVIANI, Dermeval. Formação de professores: aspectos históricos e teóricos do problema no contexto brasileiro. Revista Brasileira de Educação, v. 14 n. 40 jan./abr. 2009, p. 143-155.

SCHLATTER, Margarete. Margarete Schlatter. In: SILVA, Kleber Aparecido da; ARAGÃO, Rodrigo Camargo (Orgs.). Conversas com formadores de professores de linguas: avanços e desafios. Campinas, SP: Pontes Editores, 2013, p. 187-199.

SILVA, Sandro Márcio da; SANTOS, Cláudia Cristina Martins; SIQUEIRA, José de Oliveira. O Uso do Questionário Eletrônico na Pesquisa Acadêmica: Um Caso de Uso na Escola Politécnica da Universidade de São Paulo, II Semead - Seminários em Administração do Programa de PósGraduação em Administração da FEA/USP, 1997, p.408- 421.

Submetido em 05/12/2019

Aceito em 17/03/2020 